\title{
Problems and Solutions of Teachers' Evaluation Activities in Colleges and Universities in China
}

\author{
Ruru Yao*, Mingjun Hao \\ School of Educational Sciences, Chongqing Normal University, Chongqing 401331, China \\ *Corresponding author: Ruru Yao, 2500966571@qq.com
}

\begin{abstract}
Teacher evaluation is the action guide of teachers, which is extremely important for the development of schools. The establishment of a scientific and effective evaluation for university teachers is the key step in adapting to the current "double first-class" background in the construction of high-level teachers. Based on Habermas' theory of communicative action, this study analyzes the shortcomings and the reasons behind the current evaluation activities of university teachers in China as well as explores the standardization of these evaluation activities to meet the needs of the connotative development of higher education.
\end{abstract}

Keywords: Teacher evaluation; Utilitarianism; Digital worship; Teacher development

Publication date: October 2021; Online publication: October 29, 2021

\section{Introduction}

The delayed higher education in China and its large-scale expansion to meet the social demand for talents have brought about the dislocation of the internal management mechanism and development speed of colleges and universities. With the spread of the thought of eager for quick success and instant benefit, the evaluation activities of college teachers have also entered the barrier of the supremacy of interests, thus hindering the development process of higher education. In 2020, the Central Committee of the Communist Party of China (CPC) and the State Council issued the Overall Plan for Deepening the Reform of Education Evaluation in the New Era. The reform of college teachers' evaluation activities is the general trend as there is a need for these evaluation activities to move forward in the reform. Only by breaking the concept of utilitarianism and forming a more reasonable internal evaluation mechanism, a steady progress can be made and the real connotative development of colleges and universities can be promoted.

\section{Existing problems of college teachers' evaluation activities}

College teacher evaluation refers to a management activity in which the evaluation subject collects and analyzes relevant information and materials under the guidance of certain ideas as well as the use of certain methods to judge the facts and values of college teachers' thought, teaching, and scientific research. Only scientific and reasonable evaluation activities can promote the development of teachers and provide guarantee for the quality of talent training as well as school-running in colleges and universities. The current evaluation activities of college teachers are deeply blinded by "scientific positivism," which seriously affects the future development of colleges and universities ${ }^{[1]}$.

The data used in this study was derived from the subject research of "The Most Concerned Problems of University Teachers." A total of 88 ordinary public undergraduate colleges and universities were selected from 13 provinces and cities in the east, central, and west of China. According to the survey results, the "evaluation activities" received the most attention from the interviewed teachers, ranking first in the 
attention list of college teachers. Among them, there were 221 references to "excessive research orientation," 149 references to "one-size-fits-all assessment criteria," 119 references to "excessive quantification of indicators," 66 references to "valuing quantity over quality," and 21 references to "amateurs evaluating professionals." At present, the "scientific positivism" of college teachers" evaluation activities is as follows [2]:

\subsection{The evaluation model emphasizes results over development}

At present, the traditional reward and punishment model is still used in the evaluation of college teachers in China, whereby the results of teacher evaluation are used as an important basis for appointment, promotion, and professional title evaluation. This static evaluation model forces teachers to be in a passive position, leading to a difficulty to develop a sense of participation among teachers, affecting their autonomy and enthusiasm, as well as disregarding their original subject position in evaluation. The reward and punishment model undoubtedly plays a certain incentive role for teachers, but this material reward and external return forcibly bind teachers, reduce teachers to the utilitarian satisfaction of simply pursuing external benefits, and lose the internal incentive function of the teacher evaluation system.

\subsection{The evaluation method is more quantitative than qualitative}

Most colleges and universities adopt an assessment system that is guided by quantity, which is uniformly formulated by relevant departments at the school level and implemented by the leaders of departments at the college level. Specifically, this assessment system refines all indicators (such as the number of papers published, the weighting of the number of students and class hours taught, the number of students instructed, the number of topics declared, etc.), and each indicator has secondary or tertiary indicators. Each level under all indicators corresponds to a certain score, and the comprehensive score of the teacher can then be finally obtained. However, teachers' professional spirit, professional ethics, work value, teaching investment, and other indicators which are difficult to quantify should not be disregarded. If the value of these indicators is neglected in evaluation activities, it would easily lead to academic misconduct behaviors, such as neglecting the quality for the number of papers as well as frequent unethical choices and style of teachers.

\subsection{The evaluation content emphasizes scientific research rather than teaching}

Teaching, scientific research, and social service are the three functions of universities. However, driven by the benefits brought by the thinking of market economy, the three functions tend to be imbalance. The evaluation of university teachers is more concerned with scientific research achievements, the number of papers, the level of published journals, the inclusion in science citation index (SCI), as well as the funds and quantity of applied topics. These account for a large proportion of teachers' evaluation. Several scholars have summarized this phenomenon as "GDP of scientific research in colleges and universities." The functions of teaching and social services are neglected, especially teaching. Although teachers spend a lot of energy in teaching, they have not received corresponding attention, which leads many teachers to focus more on scientific research as it has "more benefits" and "quick results." In that case, teachers are becoming "technicians" under the performance-based salary system.

\subsection{Homogenization of evaluation criteria}

Homogenization is when the evaluation activities of university teachers adopt a similar set of evaluation activities for teachers of all types of universities, all stages, and all disciplines. This homogenization evaluation standard is chased after by colleges and universities because it greatly reduces the difficulty of 
evaluation and ensures the evaluation efficiency. Colleges and universities as well as teachers with high scores in regard to the indicators receive the corresponding ranking and reward. This "one size fits all" evaluation standard greatly deviates from the educational concept of being people-oriented, strangles teachers' creativity and personality, as well as drowns their educational enthusiasm and subjectivity.

\subsection{Single evaluation subject}

The single evaluation subject of college teachers in China mainly stems from the administration of the existing evaluation system. The relevant leaders and supervisors monopolize the management authority in the evaluation activities and use the administrative power in their hands to manage, monitor, and evaluate teachers. On the one hand, as the main body of evaluation, the leadership does not necessarily have professional evaluation quality or ability but has the status of a spokesperson or representative of the teacher evaluation. On the other hand, if all the evaluation subjects come from within the university, they are bound to lack the participation of a third-party evaluation. As a result, teachers would find it difficult to recognize the evaluation results; in addition, the respect and trust toward the results by the evaluators and the evaluated are lost. This in turn would lead to teachers' helplessness and indifference to the evaluation system, affect their independent development, and ultimately affect the quality of running a university.

In short, the current evaluation activities of college teachers in China have a serious color of scientific positivism and show a tendency of "simplification for simplicity" in the evaluation mode, standard, subject, content, and method. In the process of evaluation, efficiency and short-term interests are overemphasized, and the long-term development of teachers as well as colleges and universities are neglected.

\section{Causes of the problems in teachers' evaluation activities}

\subsection{External causes}

\subsubsection{Dissimilation of evaluation function under the orientation of university level evaluation}

Firstly, in terms of evaluation indicators, the evaluation of colleges and universities in China evaluates different levels and types of colleges and universities with the same index activity, disregarding the differences between colleges and universities. There is a tendency to focus on scientific research rather than teaching and quantitative rather than qualitative. Secondly, in terms of evaluation policies, the evaluation results of colleges and universities are closely linked to all kinds of school rankings, funds, and university positioning. College managers cannot help but bring the school into an environment of "chasing quantity and emphasizing scientific research," thus losing their own characteristics. The "digital expression" of evaluation indicators has changed into "digital worship," whereby the tool function has changed from means to purpose, and teachers' development has become an accessory. The alienation of the evaluation function of teacher evaluation has become a fetter restricting teachers' growth.

\subsubsection{Loss of academic value in poor academic ecological environment}

Academic ecological environment is an organic environment for scholars to pursue and develop academic, which has an important impact on the development of college teachers and academic development in colleges and universities. First, the social service function of universities should be based on the premise of academic freedom and should naturally promote the development of society through knowledge innovation and exploration. At present, under the pressure of market competition, many colleges and universities blindly cater to the needs of enterprises in order to improve the number of scientific research funds and project applications. Universities have become a tool to serve the interests of other organizations, and the academic environment of colleges and universities has lost its freedom and authenticity. Second, at present, all kinds of academic misconducts are rampant, and the academic ecology is seriously damaged. 
Over time, it is bound to lose its original intention of pursuing academic, resulting in the deviation of the value of college teachers' evaluation activities ${ }^{[3]}$.

\subsection{Internal causes}

\subsubsection{Colleges and universities conceptually pursue the maximization of interests}

Audit culture was developed in the 1980s under the popularity of neoliberalism. It set foot into the public management system under the "audit" mode, which has a strong regulatory effect. Its social management function is to spread a value and management concept of improving management level and paying attention to performance. This concept entered the university management system and slowly evolved into a "digital worship," where all social and teaching activities can be quantified, simplified indicators can be scored and graded, and the evaluation work of colleges and universities became "simple" and "efficient." Utilitarianism brought by the audit culture eroded the evaluation activities of college teachers, only to ensure the high efficiency of teacher evaluation. Teachers are completely nihilated in the evaluation activities, which often goes beyond the goodness of the system of pursuing teachers' subjectivity and interests ${ }^{[4]}$.

\subsubsection{Publicity of management authority under the bureaucratic management system}

The bureaucratic management system was put forward by Weber in the early 20th century. The function of this system is to maximize the efficiency of the organization. Since modern times, in order to adapt to the trend of rapid university scale expansion, the lack of bureaucracy has improved the efficiency of universities. However, the bureaucratic system with power as the core easily leads to the bureaucratization of universities, and its disadvantages are becoming more prominent. A number of scholars believe that bureaucratic management emphasizes the division of labor and power hierarchy and requires the lower level to strictly implement the orders from the higher level. This bureaucratic system of command, control, and authority is incompatible with the academic freedom of universities, only confusing the roles of administrative personnel and academic personnel. The evaluation activities of college teachers exist in the bureaucratic management system of colleges and universities with the supremacy of power, which is manifested in the administration of the evaluation subject and the efficiency of the evaluation process. The ethics of the teacher evaluation system in colleges and universities have been obscured, the subjectivity of teachers has been eliminated, and the bureaucratic management system has become a shackle that restricts the teacher evaluation system and highlights the goodness of the system ${ }^{[5]}$.

\section{Ideal outlet for college teacher evaluation}

Habermas' theory of communicative action holds that in a highly industrialized society, instrumental rationality is brought into full play. If communication rationality does not develop to a corresponding extent, instrumental rationality will degenerate into destructive irrationality. Therefore, he proposed the establishment of mutual trust through communication rationalization in order to maintain proper social order. Similarly, by establishing the interpersonal relationship of respect and trust between the evaluator and evaluated person in the evaluation activities of college teachers, teachers are no longer the "evaluated person" without the right to speak, but instead, they have a huge space for participation and professional development ${ }^{[6]}$.

\subsection{Evaluation concept: Return of people-oriented value orientation}

Ideas are the guide of action. College teachers' evaluation activities should highlight humanistic care and 
create a clear environment for teachers' personal self-worth and professional development. First, managers should establish the concept of people-oriented and fully clarify that the ultimate purpose of teacher evaluation is to promote teachers' professional development. The instrumental rationality of teacher evaluation should return to communication rationality with teachers' development as the starting point and purpose, highlighting the core position of teachers' development in the evaluation. The second is to ensure the realization of humanistic values in teachers' evaluation activities. In the process of evaluation, teachers' subjectivity should be taken as the basic point while rebuilding the realization mechanism of incentive function, stimulating teachers' work enthusiasm, promoting teachers' development in the process of evaluation, and providing opportunities to realize their professional ideals.

\subsection{Evaluation mode: Embedding of developmental evaluation mechanism}

Developmental teacher evaluation is a formative teacher evaluation mechanism. It follows the educational thought of humanistic orientation, takes teachers' professional development as the basic premise, fully reflects teachers' subjectivity in evaluation, treats their individual differences equally, as well as evaluates teachers' social activities through dynamic methods and means. Compared with the traditional reward and punishment model, its prominent advantage is that it emphasizes on the feedback regulation of teacher evaluation and assumes the growth and development of teachers as the final destination. The implementation strategy of applying developmental evaluation mechanism to teachers' evaluation activities is as follows: firstly, it is designed and implemented from a multi-dimensional perspective, and the combination of static evaluation and dynamic supervision is adopted; secondly, fair, objective, and effective indicators should be established, qualitative indicators should be emphasized; finally, an effective feedback platform should be built. Of course, rewards and punishments are indispensable. Rewards and punishments can be timely and appropriately embedded in the developmental evaluation model, so as to realize the complementary advantages of the two models and ensure the efficient operation of college teachers' evaluation model ${ }^{[7]}$.

\subsection{Evaluation content: Internal balance between teaching and scientific research}

The evaluation contents for college teachers are mainly about teaching and scientific research. At present, the phenomenon of imbalance between teaching and scientific research in college teachers' evaluation stems from the narrowing of the connotation of the term, "academic." In the late 1980s, in order to establish a more scientific academic activity, Boyer, the former chairman of Carnegie Teaching Promotion Committee of the United States, proposed four academic principles: discovery academic, comprehensive academic, applied academic, and teaching academic. Boyer stressed that "teaching academic" is more comprehensive and it is based on the other three kinds of learning. Colleges and universities should reunderstand the comprehensive meaning of the term, "academic" and realize that teaching and scientific research, as two important parts of the function and academic activities of colleges, are interdependent and complementary. In order to eliminate the scientific research hegemony in the process of university teachers' evaluation, it is necessary to improve the proportion of teaching evaluation indicators, increase the investment in the teaching work, and finally realize the complementary advantages of scientific research and teaching in the function of colleges and universities ${ }^{[8]}$.

\subsection{Evaluation criteria: Classified evaluation of "adapting to school conditions"}

Colleges and universities in China are divided into four types: teaching type, scientific research type, teaching research type, and research teaching type. Higher education has entered the stage of connotative development, which requires colleges and universities to develop hierarchically and classified. Different 
types of colleges and universities have different positioning and development goals. It is obviously a disadvantage to evaluate colleges and universities as well as teachers with unified evaluation standards. The evaluation indicators of colleges and universities should reflect differences and diversification. Based on this, colleges and universities should improve the teacher evaluation mechanism in combination with their own characteristics. Only scientific, reasonable, and persuasive evaluation activities can stimulate teachers' enthusiasm as well as make a fair and objective evaluation of teachers in the greatest sense ${ }^{[9]}$.

\subsection{Evaluation method: Quantitative and qualitative evaluations complement each other}

Marxism heavily weighs on paying attention to the organic unity of quality and quantity when analyzing anything. Quantitative evaluation for the quantification and accuracy of indicators undoubtedly improves the evaluation efficiency and reduces the difficulty, but the negative impact of excessive indicator segmentation is becoming more and more obvious. The frequent phenomena of paper plagiarism, tampering with research data, and garbage text are all caused by a single quantitative evaluation. The evaluation of university teachers should annihilate the whirlpool of "digital worship." Instead, it should embody the dedication spirit, professional ethics of teachers, and the SCI in the evaluation of scientific research achievements, as well as pay attention to the quality of papers to avoid academic bubbles. In teaching evaluation, it is not only necessary to pay attention to the teaching hours, but also to teachers' teaching investment and teaching performance. Colleges and universities should establish a special evaluation group, combined with their own positioning, to form a diversified evaluation mechanism.

\section{Conclusion}

Under the strategy of rejuvenating the country through science and education, colleges and universities, as the main place to cultivate talents, should pay more attention to the quality of teachers. The evaluation of college teachers should abandon the "digital worship" and establish a more balanced evaluation mechanism under the communication rationality, which truly reflects humanism and subjectivity. Each university should combine its own regular, give full play to its "brand" advantages, and return to the university to create a clear and free academic environment. Only in this way, a high-level university with "Chinese characteristics" can be established.

\section{Disclosure statement}

The authors declare that there is no conflict of interest.

\section{References}

[1] Zou XT, 2010, A Review of College Teachers' Evaluation from the Perspective of Intersubjectivity. Educational Review, (6): 49.

[2] Li WP, Shen H, 2016, What University Teachers Care Most About - Analysis Based on the "2014 Survey of Chinese University Teachers". China Higher Education Research, (1): 99.

[3] Feng JL, 2016, The Dilemma and Outlet of University Academic Ecology. University Education Science, (6): 101-106.

[4] Cao TS, 2019, "Five Dimensions" Problems: Evaluation of Teachers in Colleges and Universities: Consequences, Root Causes and Solutions. University Education Science, (1): 30.

[5] Chu JX, 2013, Towards School-based Management: Dilemma and Transcendence of Departmental Management in Higher Vocational Colleges. (17): 61. 
[6] Yan YR, 2017, Communication Practice and the Reconstruction of Doctor-patient Relationship: A Habermas Perspective. Journal of Tsinghua University, (3): 172

[7] Zhang Y, 2012, Difficulties and Strategies of College Teachers' Evaluation Mechanism in China. Seeker, (10): 199-200.

[8] Xiong L, 2007, Research on the Evaluation of College Teachers with Humanistic Orientation. Journal of Higher Education Management, (1): 51.

[9] Lu J, 2019, Research on the Construction of College Teachers' Evaluation Activity under the Background of "Five Dimensions". Educational Exploration, (6): 99. 